\title{
ARTICLE
}

\section{Three-Dimensional Dispersion Modeling of Liquid Radioactive Effluents around the Wolsong Nuclear Power Plant Site in Korea}

\author{
Gab-Bock LEE ${ }^{1 *}$, Ho-Sik EUM ${ }^{2}$, Doo-Ho LEE ${ }^{1}$, Yang-Hee YANG ${ }^{1}$, Sang-Hun LEE ${ }^{3}$ \\ ${ }^{1}$ Korea Electric Power Research Institute, EPCO, 65 Moonji-Ro, Yuseong-Gu, Daejeon 305-380, Korea \\ ${ }^{2}$ Ajou University, 5 Woncheon-Dong, Suwon, Gyeonggi-Do 443-749, Korea \\ ${ }^{3}$ Kyungpook National University, 1370 Sanggeok-Dong, Buk-Gu, Daegu 702-701, Korea
}

\begin{abstract}
Recently, three-dimensional models have been used for the aquatic dispersion of radioactive effluents that are released from nuclear power plants in Korea. This action is based on Notice 2008-9 from the Korean Ministry of Education, Science and Technology. In this study, radionuclide distributions around the discharge were modeled for an accurate assessment of the radiation doses to the public around the Wolsong nuclear power plant (NPP) site in Korea. These models were based on the RIAMOM (Research Institute of Applied Mechanics' Ocean Model of Kyushu University) and the EFDC (Environmental Fluid Dynamics Code). In order to verify the effectiveness of these models, tritium $\left({ }^{3} \mathrm{H}\right)$ measurements were performed in seawater samples around the modeled areas. The samples were analyzed using a liquid scintillation counting (LSC) technique after the removal of saline and organic compounds. The ${ }^{3} \mathrm{H}$ concentration of the seawater samples varied in the range of $<1.1 \sim 651 \mathrm{~Bq} / l \mathrm{depending}$ on the distance from the discharge, the time following the release of the effluents, and the tidal currents. The spatial distributions of the observed tritium concentrations were in fairly good agreement with those output by the model. The dilution factor to be used in the off-site dose calculation for a representative person was set to 2.5 .
\end{abstract}

\section{KEYWORDS: aquatic dispersion, radiological dose assessment, oceanic circulation, radioactive effluent}

\section{Introduction}

In Korea, a total of 20 units of nuclear power plants are in operation at four sites: Kori, Ulchin, Wolsong and Yonggwang. At present, 10 of new nuclear power units are under construction or in planning stages at the Kori, Wolsong and Ulchin sites. In the near future, more than 20 nuclear power units will enter operation on at the east coast of Korea.

To assess the radiological impact of radioactive effluents more accurately, the "Guideline for Investigating and Assessing the Hydrological and Aquatic Characteristics of Nuclear Facility Sites" was established by the Korean Ministry of Education, Science and Technology (MEST) in 2003.

According this guideline, three-dimensional ocean models were developed and used for new nuclear power plant siting and license renewal. ${ }^{1)}$ However, these models have not been used for radiological assessments during the normal operation of nuclear power plants.

In this study, these models were applied to calculate the dilution factor used for off-site dose assessments during the normal operation of the Wolsong nuclear power plant site. The model results were compared with tritium concentrations measured around the discharge of the Wolsong nuclear power plant site.

\section{Model Description}

To assess the aquatic dispersion of radioactive effluents near the east coastal region of Korea, it is necessary to

*Corresponding Author, E-mail:gblee@kepco.co.kr

(C) Atomic Energy Society of Japan understand the circulation of the water mass in the East Sea/Japan Sea.

The East Sea/Japan Sea circulations were modeled in an area that encompassed large parts of the East Sea/Japan Sea initially (Phase 1). A nested smaller scale model was then used within about $80 \mathrm{~km}$ from the nuclear power plant for more detailed simulations (Phase 2). Finally, the dispersions of the liquid effluents within $15 \mathrm{~km}$ from discharges of the Wolsong plants were modeled using the phase 3 model. The model domains are illustrated in Fig. 1. An outline of the models is illustrated at Table 1.

Table1. Description of Phase 1,2 and 3 models

\begin{tabular}{|c|c|c|c|}
\hline Items & Phase 1 & Phase 2 & Phase 3 \\
\hline Model & RIAMOM & RIAMOM & EFDC \\
\hline Domain & $\begin{array}{l}\text { East } \\
\text { Sea/Japan Sea }\end{array}$ & $\begin{array}{l}100 \times 100 \mathrm{k} \\
\mathrm{m}\end{array}$ & $15 \times 35 \mathrm{~km}$ \\
\hline Mesh size & $1 / 12^{\circ}(9 \mathrm{~km})$ & $1 / 36^{\circ}(3 \mathrm{~km})$ & $50 \sim 400 \mathrm{~m}$ \\
\hline Ver. levels & 20(z-level) & 20(z-level) & 7 (sigma-level) \\
\hline Bathymetry & ETOPO5 & ETOPO5 & Nautical chart \\
\hline $\begin{array}{l}\text { Sea surface } \\
\text { temperature }\end{array}$ & $\begin{array}{l}\text { Obtained by } \\
\text { ECMWF, } \\
\text { JODC, KODC }\end{array}$ & \multirow{4}{*}{$\begin{array}{l}\text { Nesting of } \\
\text { Phase } 1 \\
\text { model } \\
\text { results }\end{array}$} & \multirow[t]{3}{*}{$\begin{array}{l}\text { Nesting of Phase } \\
2 \text { model results }\end{array}$} \\
\hline $\begin{array}{l}\text { Sea surface } \\
\text { salinity }\end{array}$ & $\begin{array}{l}\text { Obtained by } \\
\text { JODC, KODC }\end{array}$ & & \\
\hline Wind stress & ECMWF & & \\
\hline $\begin{array}{l}\text { Boundary } \\
\text { data }\end{array}$ & $\begin{array}{l}\text { Inflow-outflo } \\
\text { w condition } \\
\text { from the } \\
\text { JCOPE OCM }\end{array}$ & & $\begin{array}{l}\text { Tide : } \\
\text { Observation }\left(\mathrm{M}_{2} \text {, }\right. \\
\left.\mathrm{S}_{2}, \mathrm{~K}_{1}, \mathrm{O}_{1} \& \mathrm{M}_{\mathrm{sf}}\right) \\
\text { Current : Nesting } \\
\text { of Phase } 2 \text { model } \\
\text { results }\end{array}$ \\
\hline
\end{tabular}



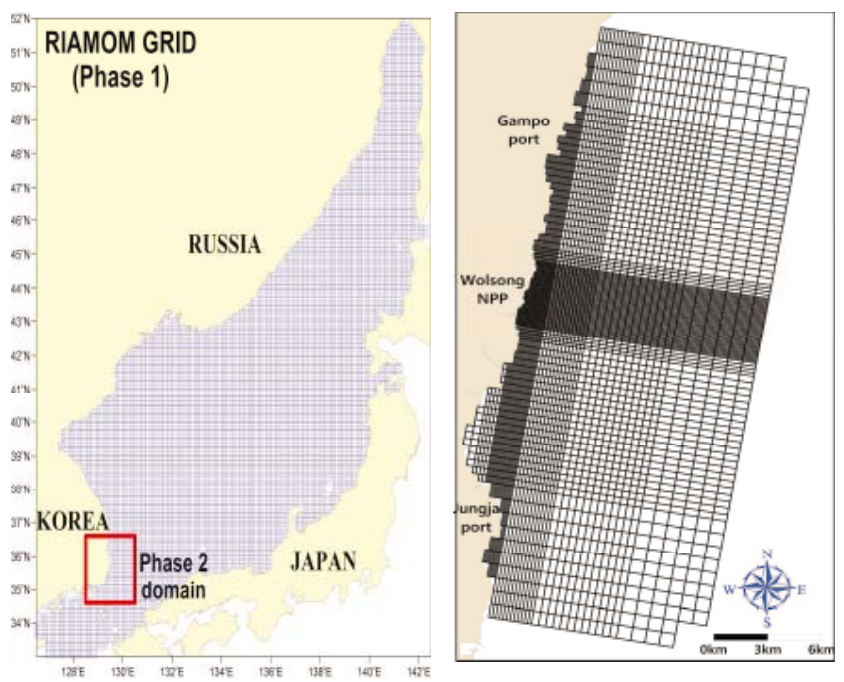

Fig. 1. Domains of Phase 1 and 2 Models (left) and Phase 3 model (right)

The Phase 1 model was based on RIAMOM (Research Institute of Applied Mechanics' Ocean Model, Kyushu University, Japan), which was shown to be applicable to the simulation of the East Sea/Japan Sea circulation. ${ }^{2)}$ The model uses primitive equations with hydrostatic approximation, and uses the Arakawa-B grid system horizontally and the z-coordinate vertically. The model domain covers the area between $126.5^{\circ} \mathrm{E}$ and $142.5^{\circ} \mathrm{E}$, and $33^{\circ} \mathrm{N}$ and $52^{\circ} \mathrm{N}$. The grid interval is $1 / 12^{\circ}$ in the longitudinal and latitudinal directions, with 20 vertical levels. This model uses a generalized Arakawa scheme, slant advection, and a mode-splitting method.

The input data were obtained from JODC (Japan Oceanographic Data Center), KNFRDI (Korea National Fisheries Research and Development Institute), and ECMWF (European Center for Medium-Range Weather Forecasts). The data observed in 2005 were used. Examples of the input data are illustrated in Fig. 2. Figure 2 shows the temperature and wind stress fields at the sea surface in winter (February in 2005).

At the inflow region around the Korea/Tsushima Strait (left of the lower part in Fig. 1), the seasonally varying volume transport of the Tsushima Warm Current (TWC) was specified. This data was prepared on the basis of regular (six time a week) monitoring of the flow variation across the Korea/Tsushima Strait from February of 1997 to August of 2002 using an ADCP (Acoustic Doppler Current Profiler) mounted on a ferry. ${ }^{3)}$ The average volume transport of the TWC was $2.65 \times 10^{6} \mathrm{~m}^{3} / \mathrm{s}$ and $1.54 \times 10^{6} \mathrm{~m}^{3} / \mathrm{s}$ in the east channel (between Tsushima island and the mainland of Japan) and $1.11 \times 10^{6} \mathrm{~m}^{3} / \mathrm{s}$ in the west channel (between Korea and Tsushima island) with strong seasonal variability.

The outgoing volume transport through the Tsugaru Strait was fixed at $1.4 \times 10^{6} \mathrm{~m}^{3} / \mathrm{s}$ throughout the calculation, taking into account the ADCP observation of Shikama. ${ }^{4)}$ The volume flowing out through the Soya Strait was then adjusted to maintain the mass balance within the domain.
The volume transports were equally distributed to each grid along the open boundaries.
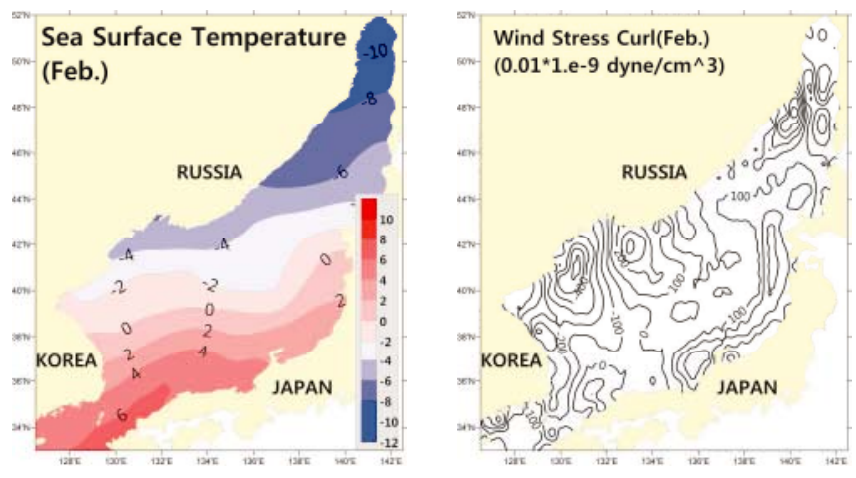

Fig. 2. Temperature, Salinity, Wind Stress, and Heat Flux Fields at the Sea Surface (Feb. 2005).

The local scale model (Phase 2) simulated the hydrodynamics and radionuclide dispersion in the coastal region outside $80 \mathrm{~km}$ from the site (Fig. 1). The input data and boundary conditions were provided by the results of the Phase 1 model with the one-nesting scheme.

The background horizontal dispersion coefficient of the Phase 2 model was determined using ARGO drifters in October 2005 around the Wolsong, Ulchin, and Kori sites. ${ }^{1)}$ The average value of the horizontal diffusion coefficients was approximately $8.5 \times 10^{6} \mathrm{~cm}^{2} / \mathrm{s}$ within $80 \mathrm{~km}$ from the coast.

The dispersions of the liquid radioactive effluents around the Wolsong site were modeled using the EFDC (Environmental Fluid Dynamics Code) developed by VIMS(Versinia Institute of Marine Science). ${ }^{5 \sim 6}$ Fig. 3 shows a flow chart of the EFDC hydrodynamic model. This is the Phase 3 model. The model domain is illustrated in Fig. 1. The input data and boundary conditions are provided through the results of the Phase 2 model with the one-nesting scheme.

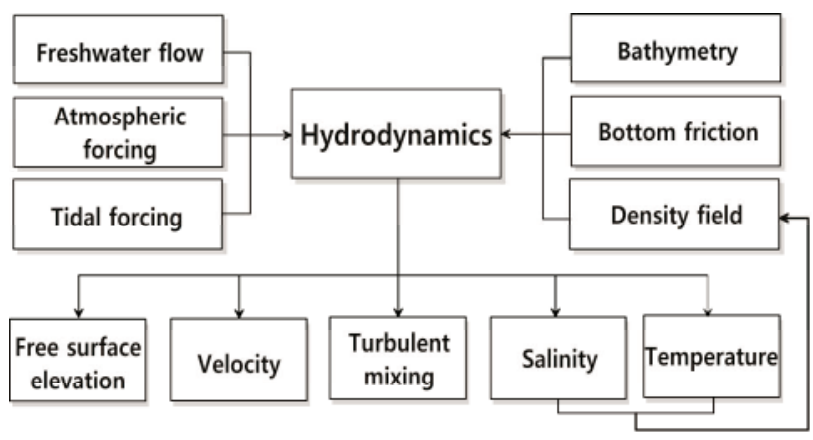

Fig. 3. Flow Chart of EFDC Hydrodynamic Model (Phase 3)

The diffusion coefficient was determined using drifters equipped with GPS, storing the location information in memory in December of 2008. An example of a drifter trace is shown in Fig. 4. The average diffusion coefficient was 
$2.9 \mathrm{~m}^{2} / \mathrm{s}$

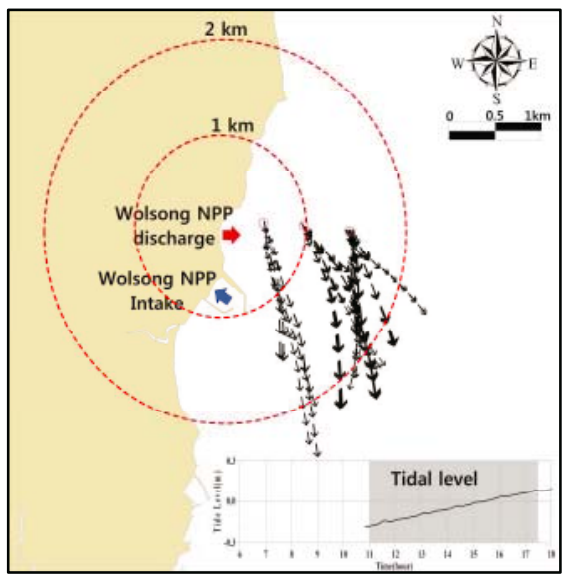

Fig. 4. Traces of Drifters with GPS

\section{Result and Discussion}

The winter (Feb.) and summer (Aug.) flow fields of the East Sea/Japan Sea at the surface level obtained from the Phase 1 model are presented in Fig. 5.
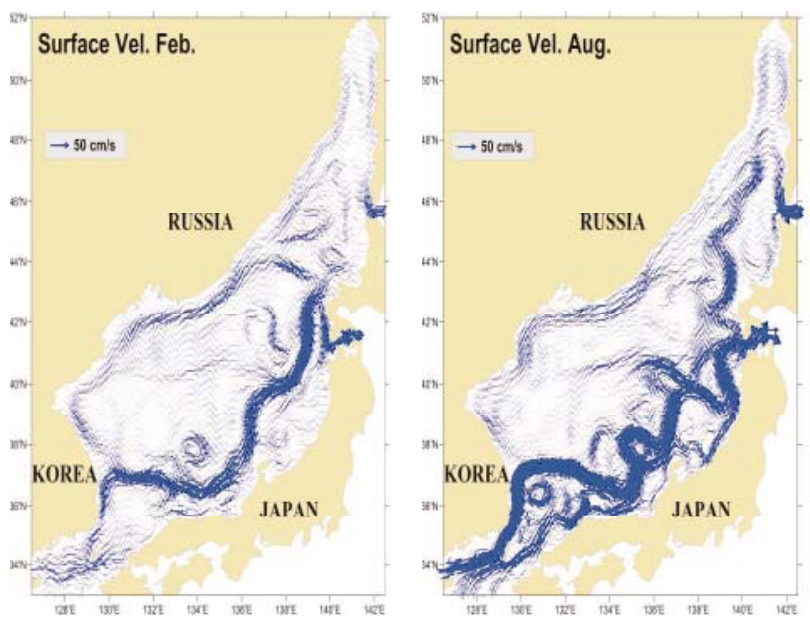

Fig. 5. Phase 1 Model Results of Surface Currents (left: Winter, right: Summer)

The model results effectively reproduced the distinct feature of circulation in the East Sea/Japan Sea, including the EKWC (East Korean Warm Current) flowing northward along the Korean coast, and the NKCC/LCC (North Korean Cold Current/Liman Cold Current) flowing southward along the Korean/Russian coast. The overall patterns of circulation were in fairly good agreement with schematic patterns of the surface circulation in the East Sea/Japan Sea as suggested previously in several papers. ${ }^{7 \sim 8)}$

The EKWC broke away from the Korean coast near $37^{\circ} \mathrm{N}$, and was stronger in August than in February. The flow fields around the Wolsong site were mainly northward currents due to the EKWC.

The seasonal distributions of the averaged dilution factors
$\left(=\mathrm{C}_{0} / \mathrm{C}\right)$ obtained by the Phase 3 model are illustrated in Fig. 6. The dilution factor refers to the ratio of the concentration (C) of a certain point to the initial concentration $\left(\mathrm{C}_{0}\right)$ of the discharge. It was assumed that a continuous release of the unit tritium occurred.

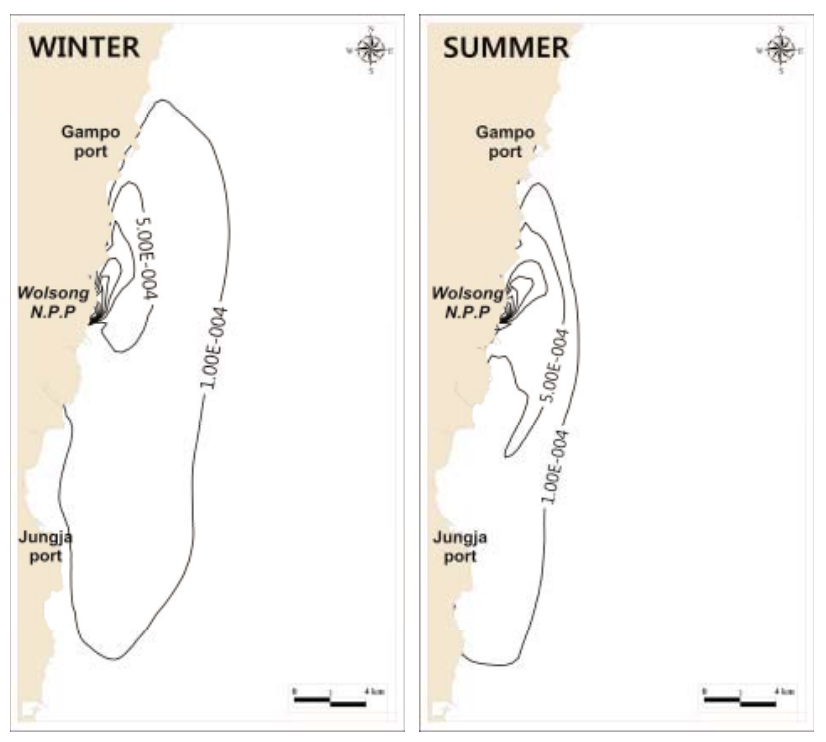

Fig. 6. Seasonal Dilution Factor Distributions obtained by the Phase 3 Model

Figure 6 shows that the effluents released from the Wolsong nuclear power plants were mostly transported northward regardless of the season due to the EKWC. The seasonal and annual dilution factors at the site boundary are illustrated in Table 2.

Table 2. Seasonal and Annual Dilution Factors at the site boundary

\begin{tabular}{|c|c|c|c|c|c|}
\hline & Spring & Summer & Fall & Winter & Annual \\
\hline North & 2.2 & 2.6 & 2.8 & 2.3 & 2.5 \\
\hline South & 14.3 & 8.0 & 7.9 & 9.1 & 9.8 \\
\hline
\end{tabular}

The northward annual dilution factor at a distance of $1 \mathrm{~km}$ from the discharge was approximately 4 times smaller than that moving to the south. In the northern part, the effluents were well diluted in the summer and fall because the EKWC was stronger than it was in other seasons.

The dilution factors of the northern part were relatively small up to $1 \mathrm{~km}$ from the discharge. These results imply that the effluents released from the Wolsong site may not be dispersed up to the site boundary $(914 \mathrm{~m})$; however over the boundary, they can be diluted easily.

The annual dilution factor to assess the off-site dose of the 'maximum individual' at the site boundary was set to 2.5 , the value at the northward side $1 \mathrm{~km}$ of the Wolsong site, which was more conservative (smaller) than that to the south.

In order to confirm performance of the EFDC model, tritium $\left({ }^{3} \mathrm{H}\right)$ concentrations were measured in seawater $(100 \mathrm{~m} l)$ sampled at the surface layer around the modeled 
area. Seawater samples at 40 sampling points were collected three times within $2 \mathrm{~km}$ from the discharge of the Wolsong site on December 12 and 13, 2008. Figure 7 shows the sampling points. $\left(1^{\text {st }}: 2008.12 .12 .10: 30 \sim 11: 54,2^{\text {nd }}: 2008\right.$. 12. $12.15: 00 \sim 16: 30$, and $\left.3^{\text {rd }}: 2008.12 .13 .11: 54 \sim 13: 16\right)$

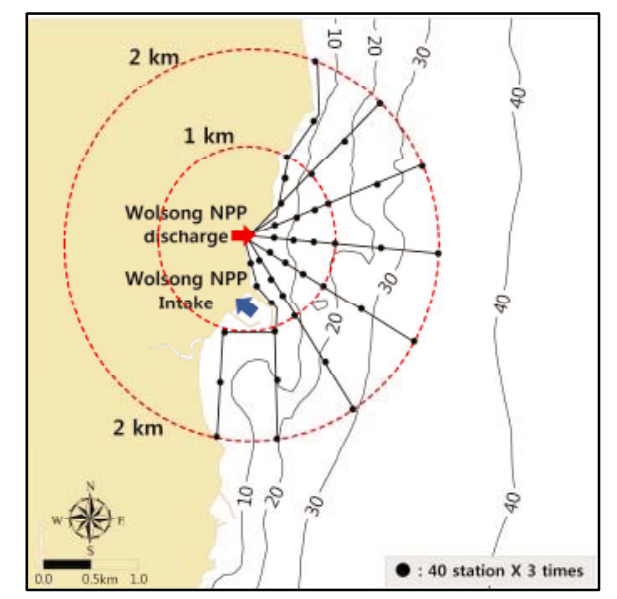

Fig. 7. Seawater Sampling Points for Tritium Concentration Measurements and Depth of Water

The samples were analyzed by LSC (liquid scintillation counter) after the removal of saline and organic compounds. The counting time for standard samples was 100 minutes. For seawater samples, it was 300 minutes. Tritium concentrations of seawater samples varied in a range of less than $1.1 \mathrm{~Bq} / l$ to $651 \mathrm{~Bq} / l$ depending on the distance from the discharge, the time after the release of the effluents, and the tidal currents.

The spatial variations during first observation for tritium around the Wolsong nuclear power plants are illustrated in Fig. 8. The figure on the left shows the observed data, while on the right are the modeling result calculated using the tritium discharge data from the Wolsong nuclear power plants.
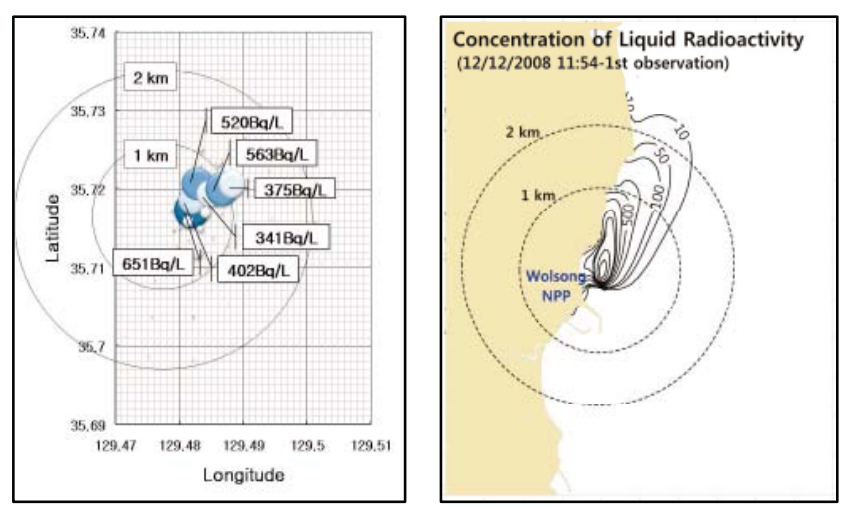

Fig. 8. Spatial Variations of Tritium around the Wolsong Site (left: Measured, right: Modeled)

In the first observation case, the observed maximum concentration at between $500 \mathrm{~m}$ and $1 \mathrm{~km}$ from the discharge of site was $563 \mathrm{~Bq} / l$ and the modeled concentration was $700 \mathrm{~Bq} / l$. In the second case (data not shown here), the observed maximum concentration was $45 \mathrm{~Bq} / l$ and the modeled concentration was $50 \mathrm{~Bq} / l$. In the third case (also not shown here), the observed maximum concentration was $12 \mathrm{~Bq} / l$ and the modeled concentration was $10 \mathrm{~Bq} / l$. These comparisons show that the proposed dispersion model can quantitatively explain the tritium distribution pattern in the studied area.

\section{Conclusion}

In this study, the aquatic dispersions of radioactive materials released from nuclear power plants under normal operation were modeled using three-dimensional models to estimate more accurately the dilution factor for an off-site dose calculation around the Wolsong nuclear power plant site in Korea. These models were based on the RIAMOM model and the EFDC model.

To compare the model results with the observation data, tritium measurements were performed in seawater samples around the modeled area. The spatial distribution patterns of tritium concentration were in fairly good agreement with the model output.

The models established in this study are considered to be good tools to simulate the dispersion of radioactive effluents from the Wolsong nuclear power plants in Korea. The annual dilution factor for use in the off-site dose calculation was set to 2.5 for the 'maximum individual' who is expected to receive the maximum radiation exposure.

\section{References}

1) Y.G. Chung, G.B. Lee, S.Y. Bang, Development of radioactive effluent dispersion model, Final report, Korea Electric Power Research Institute (KEPRI) (2006), [in Korean].

2) H.J. Lee, J.H. Yoon, H. Kawamura, H.W. Kang, "Comparison of RIAMOM and MOM in modeling the East Sea/Japan Sea circulation," Ocean and Polar Res., 25[3], 287 (2003).

3) T. Takikawa, J.H. Yoon, K.D. Cho, "Tidal currents in the Tsushima Straits estimated from ADCP data by ferryboat," Journal of Oceanography, 59, 37 (2003).

4) N. Shikama, "Variation of volume transport in the Tsugaru Strait measured by bottom-mounted ADCP," Kaiyo Monthly, 815 (1994).

5) J.M. Hamrick, "Linking hydrodynamic and biogeochemical transport models for estuarine and coastal waters, Estuarine and Coastal Modeling," Proceedings of the 3rd International Conference, M. L. Spaulding et al, Eds., New York, US, 1994, American Society of Civil Engineers, p.591(1994).

6) J.M. Hamrick, A three dimensional environmental fluid dynamics computer code: Theoretical and computational aspects, The College of William and Mary, Virginia Institute of Marine Science, Special Report-317 (1992).

7) V.G. Yarchin, "Study state of the Japan Sea, In: Problems of Oceanography," ed. by V. Pokudov, Hydrometeoizdat, Leningrad, p46 (1980).

8) K. Kim, K.Y. Kim, D.H. Min, Y. Volkov, J.H. Yoon, M. Takematus, "Warming and structural changes in the East (Japan) Sea: a clue to future changes in global oceans?," Geophys. Res. Lett., 28, 3293 (2001). 